\title{
Pablo Montoya y la celebración de lo excéntrico ${ }^{1}$
}

\author{
Mónica MARINONE \\ Centro de Letras Hispanoamericanas, CELEHIS \\ Universidad Nacional de Mar del Plata \\ mmarinone@gmail.com
}

\begin{abstract}
RESUMEN
El colombiano Pablo Montoya es, además de escritor, traductor y músico (dejó de interpretar en orquestas sinfónicas cuando se decidió definitivamente por el primer "oficio"), y los datos biográficos pretenden abonar ciertos intereses de este ensayo, donde examino narrativas de Montoya que despliegan sus saberes. Como distintos escritores de este continente, asedia nuestros "principios" (el siglo XIX, por ejemplo) y un vasto archivo (Occidente), aunque de manera infrecuente: su elección de temas y operatorias revelan su apuesta a una estética refinada y disruptiva que traza líneas hacia tradiciones y repertorios inesperados, y si ingresa de modo oblicuo en problemas recurrentes de nuestra literatura (la violencia, el destierro, el desarraigo, el tránsito, lo transitorio...), a la par lo hace desde imaginarios excéntricos, que implican una latinidad poco o nada considerada por latinoamericanos. Sus novelas La sed del ojo (2004), Lejos de Roma (2008) y Tríptico de la infamia (2014) son ejemplares en estos sentidos.
\end{abstract}

Palabras clave: Pablo Montoya, fotografía, pornografía, París, Colombia.

\section{Pablo Montoya and the celebration of the eccentric}

\begin{abstract}
The Colombian writer Pablo Montoya is also a translator and a musician (he abandoned symphonic orchestras when he opted definitely for the first "profession"). His biographical information helps us to justify the scope of this essay, which aims at analyzing the narratives in which Montoya displays his wide variety of knowledge. As well as different writers in South America, he besieges our "cornerstones" (for example, the $19^{\text {th }}$ century), and a huge archive (Occident itself), but in a rather unusual way: his choice of subjects and

${ }^{1}$ Una versión reducida de este ensayo es incluida como post scriptum y por pedido de Pablo Montoya, en la reedición (2015) de su novela La sed del ojo por una editorial independiente de la ciudad de Mar del Plata (Argentina). Vale destacar que dicha editorial solicitó a Montoya su novela antes de que obtuviera el Premio Rómulo Gallegos (2015). La notación completa se incluye en Referencias Bibliográficas.
\end{abstract}


methodologies reveals that he is based on a delicate and disruptive esthetics that establishes connections with unexpected traditions and repertoires. On the other hand, Montoya gets in touch obliquely with recurring themes in Latin American literature, such as violence, uprooting, transience, etc., together with eccentric modes of imagination that imply a Latin identity that has been hardly considered in Latin America. His novels La sed del ojo (2004), Lejos de Roma (2008), and Tríptico de la infamia (2014) are concrete examples in this sense.

Key words: Pablo Montoya, photography, pornography, Paris, Colombia.

Atravieso los pasajes de París... Ciudad amada y horrible. Reflejo de algo que busco con minucia y jamás encuentro. Escurridiza siempre. París. Fruta podrida. Llena de semillas infinitas.

I.

Hacia 1939, Walter Benjamin está exiliado en París. Entre 2000 y 2002, el narrador colombiano Pablo Montoya escribe un breve texto cuyo título es "Benjamin", del cual tomo el epígrafe. ${ }^{2}$ Es una de las estampas biográficas de su excéntrico volumen Cuaderno de París (2006: 106) dedicado, ambiguamente, "a los amigos de allá". Hermanado, según dice en una entrevista (Marcos Fabián 2011), al Cuaderno de Nueva York de José Hierro, nada casualmente se abre con una frase de César Vallejo: "Hay, madre, un sitio en el mundo que se llama París. Un sitio muy grande y lejano y otra vez grande" (Montoya 2006: 9). Es un volumen de inflexión autobiográfica donde cohabitan crónicas, impresiones, notas, estampas... Una cartografía personal densa de lo visto / leído / vivido / imaginado,

2 Pablo Montoya (1963) nació en Barrancabermeja (Colombia) y está radicado en Medellín. Es escritor, traductor y profesor universitario. Entre sus relatos destacamos: Cuentos de Niquía, en edición bilingüe, (1996), Habitantes (1999 y 2003), Razia (2001), La sinfónica y otros cuentos musicales (1997), Adiós a los próceres (2010), Réquiem por un fantasma (2006), El beso de la noche (2010), y sus novelas La sed del ojo (2004), Lejos de, Roma (2008), Los derrotados (2011) y Tríptico de la infamia (2014). Ha escrito los ensayos Novela histórica en Colombia 1988-2008, entre la pompa y el fracaso (2009) y Música de pájaros (2005), así como prosa poética: Sólo una luz de agua: Francisco de Asís y Giotto (2009); Trazos (2009); Cuaderno de París (2006) y Viajeros (1999 y 2011). Ha recibido premios y reconocimientos: entre otros, la beca para escritores extranjeros en 1999 otorgada por el Centro Nacional del libro de Francia por su libro Viajeros (1999); en el 2000, el premio Autores Antioqueños por su libro Habitantes (1999); su libro Réquiem por un fantasma fue premiado por la Alcaldía de Medellín en el 2005, en 2008 obtuvo la Beca de investigación en literatura, otorgada por el Ministerio de Cultura y, en 2015, el Premio Rómulo Gallegos. Su blog: http://www.pablomontoya.net. 
y de pasajes entre sitios, figuras o tiempos. Antes de "Benjamin" incluye un texto denominado "Baudelaire", donde las enumeraciones se agolpan y dan profundidad a una escena, en París, que reúne a un enunciador indefinido y a un Baudelaire casi mudo, errático, sumido en la alucinación del éter, el opio, el láudano, quien pronuncia una palabra poderosa: "trashumancia". Y después, por boca del otro, frases del mismo tenor: "dijo que no había mejor hogar que la calle. Ni siquiera el corazón de una mujer. Ni siquiera la música. Ni siquiera el mar y las nubes. Ni siquiera el poema que es escurridizo" (Montoya 2006: 94). Es una insólita calle donde Montoya traza "un reguero de baúles" a raíz de "otra mudanza" de Baudelaire, baúles llenos de cosas, entre ellas, "la fotografía de Nadar donde él era el misterio, el sufrimiento, la horrenda belleza de un maldito" (93).

La sintaxis que reconstruyo -París / Benjamin / Baudelaire / Nadar- restituye un imaginario que resulta también un "reguero" hacia obsesiones de Montoya, cristalizadas en su primera novela, La sed del ojo de 2004. El Baudelaire de Nadar sería una de esas fotografías antiguas a que se refiere Benjamin en su "Pequeña historia de la fotografía", esas que invitan a hacer "calas", ejercicio que Montoya atiende para escribir muchas de sus estampas biográficas. Pero, en este caso, me interesa otro de sus juegos: el aprovechamiento de ciertos intereses de Benjamin (Baudelaire fue uno; la fotografía y es claro, las calles de París, su capital del siglo XIX). Son intereses y operaciones que Montoya procesa de modo notable para escribir esta primera novela que abre una tendencia disruptiva en el contexto colombiano contemporáneo, tendencia abrevada desde otras puestas suyas como Lejos de Roma y Tríptico de la infamia ${ }^{3}$.

II.

Un policial erótico. Es su frecuente definición de La sed del ojo y la frase no desacomoda; pero cuando iniciamos su lectura surge el desconcierto porque ficcionaliza un hecho poco conocido, que se data en el Epílogo:

En octubre de 1860, más de cuatro mil fotografías obscenas fueron confiscadas en el domicilio de Auguste Belloc por la policía de París. De este decomiso solo subsisten hoy veinticuatro vistas estereoscópicas conservadas en el Infierno del Departamento de Estampas y de Fotografía de la Biblioteca Nacional de Francia. Esta novela intenta recrear tales acontecimientos (93). (Subrayado mío)

Si no salteamos las páginas hasta el fragmento citado, si somos lectores entregados hasta el Epílogo, la atmósfera del Segundo Imperio nos convoca desde un epígrafe (en francés) que desoculta a Baudelaire. Es una frase del Salón de 1859

${ }^{3}$ Los derrotados, la tercera novela de Montoya (2012), es un punto de fuga en dicha tendencia. 
entramada en el título de la novela: "ojos ávidos se inclinan sobre las mirillas del estereoscopio como sobre los tragaluces del infinito"4. La palabra estereoscopio y derivado (me refiero a vistas estereoscópicas) se reitera, abre y cierra el volumen, operando respecto de alguna hipótesis: si La sed del ojo se articula sobre dos tipos discursivos (policial y erótico), esta duplicidad en simultáneo remedaría el juego estereoscópico, que obliga a mirar, con ambos ojos, dos imágenes de un objeto, las cuales al fundirse producen sensación de relieve. La convocatoria a adentrarse en un texto donde el relieve es protagónico porque le es inherente como tejido, se subraya por un montaje sobre tres dominios coexistentes y entramados (justicia, arte y ciencia). Montaje polifónico, encarnado en las tres voces que controlan el enunciado, de modo alternativo o azaroso: Madelaine, el policía perseguidor, Belloc, el fotógrafo perseguido, y Chaussende, el médico, interlocutor de Madelaine; en realidad, tres voyeurs compulsivos. Pero entre esas voces, en foco o en resonancia, leo a Baudelaire y a Benjamin, dos pilares que animan una anécdota acabada y aparentemente sencilla, pero conducente a un universo de cuestiones atravesado por una presencia secreta (parafraseo a Benjamin respecto de Baudelaire), una ciudad (una sociedad) aludida desde partes. Por ello apelo a una frase de Montoya sobre el cine de Andréi Tarkovski para cerrar mejor mi idea sobre esta novela: "Como fluye un río, sereno en apariencia, pero turbulento en su interior" (Montoya 2003: 8).

Me he preguntado por estos "anacronismos" frecuentes de Montoya que, por ejemplo, propician el incógnito de la voz autoral (marca de Baudelaire que, según Benjamin, era su ley) ${ }^{5}$. También, por la atracción de una dupla (policial/erótico) transgredida y puesta en crisis aquí. Y por la índole del material (fotografías obscenas) del que diré solo que Robert Darnton abre su Coloquio de los lectores (2003) con un ensayo, "Sexo para pensar" (61) cuyo título toma de Claude LéviStrauss ${ }^{6}$. Darnton indaga el patrimonio del Enfer, inaccesible para casi todos hasta 1980, el lugar donde se conservaron los daguerrotipos de Belloc que interesaron a Montoya $^{7}$. Darnton señala algo importante: el sexo (y agrego, la pornografía) no es

${ }^{4}$ El epígrafe dice: «D’yeux avides se penchaient sur les trous du stéréoscope comme sur les lucarnes de l'infini".

${ }^{5}$ Copio la cita: "El incógnito es la ley de su poesía" (Benjamin, 117).

6 "En El pensamiento salvaje [...] sostiene que muchos pueblos no piensan como lo hacen los filósofos, por medio de la manipulación de abstracciones. En cambio, piensan con las cosas- con cosas tangibles de la vida diaria [...], o con cosas imaginarias salidas de los mitos y del folclore [...] El sexo es a la gente común lo que la lógica es para los filósofos: ayuda a que las cosas adquieran un sentido. Y esto fue lo que hizo el sexo con gran eficacia durante la época de oro de la pornografía, de 1650 a 1800, en Francia sobre todo" (Darnton, $61)$.

7 Ante mi pregunta por los materiales que impulsaron la escritura de La sed del ojo, Montoya contestó que en diciembre de 2002 había "tropezado" con el libro Obscénités, 
solo el tema, sino la herramienta. Y cobra peso el juego con un tema/archivo que genera placer al lector, restaura una zona potente y vuelve esta excéntrica novela, llave y clave (Benjamin usaba la palabra clé). Clé para pensar, de modo oblicuo, nuevas significaciones, nuestra época.

La atracción de la alta poesía francesa del siglo XIX no es original; otros narradores la rondan para recuperar un ethos, impulsos de ciertos padres. Roberto Bolaño $^{8}$, por ejemplo, dice que prefigura los grandes problemas de la cultura occidental: la revolución, la muerte, el aburrimiento... Pero en Montoya es original el modo como la procesa: una extensión que compele a no dejar la lectura y el regodeo en una atmósfera (Le folie Baudelaire diría Roberto Calasso ${ }^{9}$ ) que la estética modernista le ayuda a restaurar, todo efectuado en un texto completo. Montoya cumple el conocido mandato de Baudelaire cuando lee a Edgar Allan Poe (que Benjamin también rescata): toda literatura que se rehúse a marchar fraternalmente entre la ciencia y la filosofía es una literatura homicida y suicida. Esta combinatoria satura La sed del ojo a partir de los dominios ciencia / arte / justicia. En superficie, pone en escena cuestiones como la fascinación del mirar de los hombres, el cuerpo femenino / objeto, la prostitución y la enfermedad, la belleza y la corrupción... En sesgo, conceptos y vínculos productivos: flâneur (escritor / poeta moderno), fotógrafo / coleccionista / cazador furtivo / detective / burgués hipócrita; capitalismo y deseo, lo privado y lo público, deseo y poder, ley e interdicto, y es claro, la "concupiscencia de los ojos", vía de la "concupiscencia del alma" de San Agustín (y antes, de Platón), apetito de conocer para el cual los ojos serían la entrada.... Me parece que con este policial-erótico, cuyo centro (fotografías pornográficas) exuda una ociosidad de la que Baudelaire hace gala (como dice Benjamin, hace su método de trabajo), Montoya rompe "hechizos" y obliga a pensar.

III.

Hablar de mi oficio, y esto lo he sostenido siempre, es hablar de poesía. Las dos son intentos de atrapar algo que es vago para la mayoría de los hombres. (Montoya 2004: 20)

Quien "habla" es Belloc, el fotógrafo perseguido. La cita conlleva relieve: en superficie surge la anécdota, en susurro, diversos planos asedian, aun la enunciación. Porque Montoya parece hablar de sí mismo cuando escribe narrativa y la poesía es su motor. Es otra de sus marcas excéntricas por la sugerencia (la

Photographies interdites d'Auguste Belloc, publicado en 2001 por Albin Michel, Bibliothèque Nationale de France, y que escribió la novela en los primeros meses del 2003.

${ }^{8}$ Me baso en "Literatura + enfermedad= enfermedad".

${ }^{9}$ Esta frase da título a su exhaustivo ensayo. 
insinuación), el refinamiento, y el culto de la imagen y la imaginación, para Baudelaire, la reina (la más científica) de las facultades porque comprende la analogía universal. La estética modernista, visible en La sed del ojo, conviene a Montoya (subrayo: una estética sin opulencias), dadas la índole de la anécdota que ficcionaliza y la atmósfera que explora, pero además por ciertas convicciones que resurgen en sus textos. Pienso en la "aristocracia intelectual" dariana (sumadas las reflexiones y debates posteriores sobre dicha frase), o en la apropiación de la alta cultura europea y en no sentirse ajeno. Susana Zanetti decía a Montoya: “...vos encarás el relato desde otras perspectivas... y tus modulaciones líricas mitigan las nostalgia o la angustia con cierta esperanza alentada por el arte y la música"10.

Me parece que es aplicable a Montoya la frase del Lautréamont en los sentidos que César Aira (2000: 167) le atribuye: "'La poesía debe ser hecha por todos, no por uno', significa que ese 'uno', cuando se ponga en acción, hará todas las artes, no una". Lo cito porque los saberes de Montoya se tiñen mutuamente: literatura, pintura y música se le mezclan (fue músico sinfónico hasta que se dedicara de lleno al oficio de escritor $)^{11}$. De ahí que asuma la estética modernista como herencia "conveniente" ("herencia" en sentido derridiano, para lo que no hay comodidad garantizada, por eso hablo de saberes ${ }^{12}$ ). Montoya revisita el pasado de Occidente y se regodea en lo diferente, absorbe cuestiones e imaginarios distintos o distantes. Importa anotar que en Lejos de Roma asedia el centro de la latinidad desde una recreación del destierro de Ovidio que Augusto decretara, a partir de la revisión del mismo Ovidio en Tristia y Epistulae ex Ponto; y que en Tríptico de la infamia aborda las guerras de religión entre protestantes y cristianos (siglos XV y XVI)

${ }^{10}$ Cito la referencia completa de Susana Zanetti en una plenaria del IV Congreso del Celehis (Mar del Plata, Argentina, 2011) que tuve el gusto de coordinar: "la actual novela colombiana sobre la violencia se concentra en lo inmediato, en "documentar" una realidad brutal [...] vos encarás el relato desde otras perspectivas [...] y tus modulaciones líricas mitigan la nostalgia o la angustia con cierta esperanza alentada por el arte y la música". En Borradores de "Susana Zanetti conversa con Pablo Montoya". La mención de Zanetti es, además, un homenaje a su memoria pues conocí la narrativa de Montoya por la novela que ella me regalara, Lejos de Roma, sobre la cual escribió un artículo que integra el volumen internacional publicado poco después de su muerte, en agosto de 2013. Lo incluyo en las Referencias bibliográficas

${ }^{11}$ Los volúmenes Viajeros, Trazos y Música de pájaros son buenos ejemplos de los saberes de Montoya. Viajeros (1999) fue reeditado en un libro-objeto que incluye semblanzas, ilustraciones y grabaciones de los textos.

${ }^{12}$ Vale reponer su definición en Espectros de Marx: "Al explicarme de manera insistente sobre ese concepto o esa figura del legatario, llegué a pensar que, lejos de una comodidad garantizada que se asocia un poco rápido a dicha palabra, el heredero siempre debía responder a una doble exhortación, a una asignación contradictoria: primero hay que saber y saber reafirmar lo que viene antes de nosotros" (Derrida, 5). 
desde las vidas de tres pintores (y/o grabadores) protestantes europeos ${ }^{13}$. Desde lo compositivo, en La sed del ojo se sitúa como si fuera un modernista en los orígenes de nuestro Modernismo (tal como César Aira respecto de las Vanguardias). Y me refiero al Modernismo como piso estético que se atrevió a la afluencia cultural cosmopolita, en especial francesa, y bregó por la autonomía y el saber del arte ${ }^{14}$. Benjamin comentaba que "Baudelaire quería ser leído como un antiguo" (108). "Muy antiguo y muy moderno" decía Rama (24) de Rubén Darío, y mutatis mutandis, quizás sea la insignia que Montoya desea portar.

Desde estas observaciones regreso (y nuevamente salvo las distancias) a los "anacronismos" de Benjamin que describe Didi-Huberman, capaces de restaurar la experiencia / acción respecto del suceder de la historia: qué permite pensar esta novela / archivo / clé hoy. Obliga a muchas preguntas y a una, inquietante, que fluye en las conversaciones de Madealine / Belloc/ Chaussende donde se actualizan posiciones del cenáculo Baudelaire, cuando la daguerrotipia surgía y se

${ }^{13}$ En Los derrotados, en cambio, Montoya flirtea con Colombia y su endémico problema de la violencia (de continuo tratamiento en narrativas consagradas y no tanto) desde historias de vida que plasma en dos tramas discontinuas y complejas reenviando, centralmente, a las guerras de independencia y a los movimientos guerrilleros de su país, en particular el Ejército Popular de Liberación (EPL). Se trata de las vidas del naturalista Francisco José de Caldas, con foco inicial en su captura y espera de fusilamiento por los españoles, y de tres personajes ficticios, quienes, además de acercarse a este movimiento con grado diverso de compromiso, introducen la botánica, la literatura y la fotografía, tres dominios que coexisten y se entraman en este texto proteico y polifónico. Lo exploro en un artículo que cito en las Referencias bibliográficas.

${ }^{14}$ El ensayo de Zanetti sobre Rubén Darío que cito en las Referencias bibliográficas ha sido iluminador respecto de estas anotaciones. Las frases siguientes (en especial lo que subrayo) sintetizan de algún modo la herencia que atribuyo a Montoya: "Darío se convertirá en jefe de ese grupo cultural que basa sus discursos, de firmes convicciones cosmopolitas, en definirse como artista moderno, conflictivamente instalado en las tensiones entre vocación y mercado" (526). "El refinamiento de la sensibilidad a través de la sensación y la percepción, tamizadas por el trabajo con la sugerencia, alimentaba el sueño y el ensueño, creaba nuevos espacios a la imaginación, a la intimidad, al reino interior, así como alentaba el placer y el erotismo, haciendo de la energía sexual el principio rector del universo" (532).

En una entrevista muy reciente, Montoya dice: "Uno de los mayores logros del modernismo es su apuesta por la autonomía del arte y, en este sentido, su defensa del valor estético. Los modernistas poseen un rasgo fundamental que yo sigo sin hesitaciones: su preocupación por una escritura poética que es, a la vez, consciente de una particular búsqueda de la belleza. Esta empresa, cuyo objetivo fue la necesaria secularización del arte, se hizo en un contexto excesivamente nacionalista, y se vio como una posición escapista. Se creía que los modernistas desdeñaban los contornos de la identidad americana. Pero, en realidad, no la menospreciaron sino que la estaban ampliando de modo inquietante". (Montoya 2015). 
preguntaban "qué es el arte". Es la pregunta frente a nuevos formatos y registros. Y pienso en Néstor García Canclini o en Ticio Escobar, a quien Canclini intertextualiza desde la frase "el arte fuera de sí" que abre La sociedad sin relato. Es una pregunta que escudriña el poder y el peso del mirar desde nuevos códigos visuales (como cuando la fotografía emergía) y una nueva ética de la visiónposesión. Ambos también parecen "anacrónicos" cuando tientan respuestas: Canclini regresa a Borges y propone el arte como lugar de la inminencia. ${ }^{15}$ Escobar, en cambio, recupera el concepto de aura de Walter. Benjamin:

La fotografía erótica no es únicamente el resultado en el papel o en el vidrio... Incluye la comunicación entre la modelo y el fotógrafo. Y si ésta es afortunada, como una aureola indefinible cubre todo el ámbito de la imagen obtenida (Montoya 2004: 34). (Subrayado mío).

Es Belloc de nuevo y, a través suyo, Montoya -como Escobar- atrae a Benjamin cuando intenta explicar el aura (la aureola indefinible) ${ }^{16}$. Las afiliaciones de Montoya arrasan prejuicios sobre la pornografía rompiendo con la vulgaridad y lo rutinario que la temática pudiera alentar. Pero además rompe con rutinarias temáticas de su contexto (parecen las antiguas aspiraciones darianas). "Irrepetible aparición de una lejanía, por cerca que ésta pueda estar", dice Benjamin del aura, y la frase quizás guiara a Montoya cuando "cala" en la "fotografía", la "pintura" y la "música" interferidas en la descripción de ciertas escenas de La sed del ojo. Así construye lectores / voyeurs / escuchas, o despierta curiosidad desde la insinuación y el dato desconocido subrayando su apuesta a volvernos lectores-extranjeros, provocando "extrañamiento y descubrimiento" (son dos palabras de Aira en su ensayo "Exotismo"). En esta hermenéutica / erótica despliega una función política (la popularización de lo raro es el objeto de toda educación, sentenciaba Alfonso Reyes cuando pensaba a Mallarmé y a Darío). Montoya despedaza modos mecánicos de leer, hoy habituales, obliga a una lectura sosegada que si la poesía reclama, el acto del mirar contemplativo propicia, y reenvía primero a Friedrich Nietzsche, después a Roland Barthes cuando sentenciaba que para leer a ciertos autores es necesario reencontrar el ocio de las antiguas lecturas, es decir, ser lectores aristocráticos. Es la propuesta del cine de Tarkovski que Montoya valora y

${ }^{15}$ Cito a García Canclini: "el arte es el lugar de la inminencia. Su atractivo procede, en parte, de que anuncia algo que puede suceder, promete el sentido o lo modifica con insinuaciones. No compromete fatalmente con hechos duros. Deja lo que dice en suspenso". (12)

16 Dice en "Pequeña historia de la fotografía": "Se trata de esta aureola a veces delimitada, tan hermosa como significativamente, por la forma oval, ahora ya pasada de moda, en que se recortaba entonces la fotografía. ¿Pero qué es propiamente el aura? Una trama muy particular de espacio y tiempo: irrepetible aparición de una lejanía, por cerca que ésta pueda estar" (Benjamin). 
de quien dice alguna frase que le sería aplicable: "en el centro de (su) búsqueda pictórica se expresa (su) concepción pilar [...] de la imagen" (Montoya 2003) hacia el rescate de sociedades minadas de las grandes ciudades (que Baudelaire logró entrever, un gesto que Benjamin subraya), desde esas "modulaciones líricas" a que se refería Zanetti. Y agrego, unas modulaciones siempre discretas, esas semillas infinitas del epígrafe que abre este ensayo, las que impondrían el deseo, que es la "esperanza"17.

\section{BIBLIOGRAFÍA}

AIRA, César.

1993 "Exotismo", Boletín del Centro de Estudios de Teoría y Crítica Literaria, $\mathrm{n}^{\mathrm{o}}$ 3, pp. 73-79.

2000 "La nueva escritura", Boletín del Centro de Estudios de Teoría y Crítica Literaria, $\mathrm{n}^{\circ}$ 8, pp.165-170.

BENJAMIN, Walter.

1972 Iluminaciones II (Baudelaire). Madrid: Taurus.

1989 "Pequeña historia de la fotografía", Reflexiones marginales, año 3, $\mathrm{n}^{\mathrm{o}} 14,1989$.

BOLAÑO, Roberto.

2003 "Literatura+enfermedad=enfermedad", en El gaucho insufrible. Barcelona: Anagrama.

CALASSO, Roberto.

2012 La Folie Baudelaire. Barcelona: Anagrama.

DARNTON, Robert.

2003 "Sexo para pensar", en El coloquio de los lectores. México: Fondo de Cultura Económica, pp. 61-96.

DERRIDA, Jacques.

1995 Espectros de Marx. Madrid: Trotta.

DIDI HUBERMAN, George.

2008 Ante el tiempo. Buenos Aires: Adriana Hidalgo.

ESCOBAR, Ticio.

2004 El arte fuera de sí. Asunción: CAV/ Museo del Barro / FONDEC. GARCÍA CANCLINI, Néstor.

2010 La sociedad sin relato. Madrid: Katz.

${ }^{17}$ Son palabras y conceptos del poeta Arseni Tarkovski, padre (maestro) del cineasta. 
MARINONE, Mónica.

2015 "Post scriptum. Una lectura excéntrica", en Pablo Montoya, La sed del ojo. Mar del Plata: Puente Aéreo, pp.161-171.

2016 "Pablo Montoya: Los derrotados", Hispamérica, $\mathrm{n}^{\circ} 133$ [En prensa].

MONTOYA, Pablo.

2003 "Aproximaciones a Tarkovski", Revista de Extensión Cultural de La Universidad Nacional de Colombia, $\mathrm{n}^{\circ}$ 47, pp. 7-18.

2004 La sed del ojo. Medellín: EAFIT.

2011 "La palabra desnuda". Entrevista realizada por Marcos Fabián, Auroraboreal, 16 de setiembre de 2011.

2015 "Descubriendo América". Entrevista realizada por Enrique Foffani, Radar Libros, 6 de diciembre de 2015.

RAMA, Ángel.

1976 "El dictador letrado de la revolución latinoamericana", en Los dictadores latinoamericanos. México: Fondo de Cultura Económica, pp. 20-41.

ZANETTI, Susana.

2008 "El Modernismo y el intelectual como artista: Rubén Darío", en Altamirano (dir.), Myers (ed.). Historia de los intelectuales en América Latina I. Madrid: Katz, pp. 523-543.

2013 "Lejos de Roma", en Mónica Marinone y Gabriela Tineo (coords.). Noticias del diluvio. Textos latinoamericanos de las últimas décadas. Mar del Plata: Editorial de la Universidad de Mar del Plata (EUDEM), pp. 167-176. 